\title{
The future of industry with collaborative robots
}

\author{
Miriam Matúšová ${ }^{1}$, Marcela Bučányová ${ }^{1, *}$, and Erika Hruškováa," \\ ${ }^{1}$ Slovak University of Technology, Faculty of Material Science and Technology, Institute of \\ production systems, J. Bottu 25, 917 24, Trnava, Slovak Republic
}

\begin{abstract}
Rapidly changing user requirements, improving of quality of life or increased safety at work are all arguments for introducing flexible automation that replaces strenuous or dangerous work. Industrial robots with adaptive directing are now deployed to most industries due to their large range of uses. Their main addition for manufacturing is to eliminate downtime of complete operating and manipulating production process, to make easier all particular operation in accordance with ergonomics. The paper describes comparing between conventional industrial robot and collaborative robot.
\end{abstract}

\section{Introduction}

From the point of view of production of technology design, seriality, stability of occur products in production, material of the product and its influence on the degree of fluency and rhythm of the technological process are important. It is necessary to solve the worthiness and suitability of the product for automated production and the qualitative characteristics determining the competitiveness of the products. It is important to ensure that the design of the production of a particular product is necessary continuity by the basic activities to create the technological process of production. Currently, it is necessary to solve the automation of production or the final assembly process of obtaining of the suitable product for export [1]. Continuously increasing work productivity requires the introduction of automation into the production or assembly process. Replacing a man with automated machines is especially suitable for monotonous work, work in noisy, hazardous or otherwise harmful environment. Furthermore, it is advisable to replace a person where automation will increase the quality and accuracy of the work. Fluctuations in man's performance due to physical or mental state, relatively small force or light vulnerability are properties that should not be in the production process. Automation of the production process can greatly reduce the production costs of products and thus reduce the resulting product price. Automation increases the production flexibility and shortens production times. Automation cannot be restricted to the selected machine but needs to be understood in a complex way. These include automated transport, material manipulation, tool change, controlling and measurement and others. Automation of the technological processes can be solved using universal, dedicated devices or their elements, or a suitable combination of all mentioned options. The solution of any particular automation application needs to be judged on the technological as well as the economic side [2].

\footnotetext{
*Corresponding author: marcela.bucanyova@,stuba.sk, erika.hruskova@,stuba.sk
} 
The main purpose of this article is to obtain the main characteristics of conventional industry and collaborative robots via worth criterion and thanks to this it is easier to choose what type of robots is more suitable for a particular type of production.

\section{The industrial robots}

The base opportunities of production robots to different from other machines:

1. Final orientation - to define and subdivide partial sequence targets. The robot then begins to plan the necessary activities and perform them so that the partial targets are synchronized.

2. Flexibility - the robot's ability to adapt to its surroundings can be achieved by automatically exchanging of individual mechanical components - end effectors and/or selecting of control algorithms.

3. Programmability - by this the robot becomes a universally usable machine.

4. Automatic operation - a robot can work without constant and immediate human support, so according to a particular program he can perform a complex sequence of tasks.

5. Exchange of information with the environment - according to exchange of information with the environment, the robot the robot recognizes the state of the surroundings and influences the environment in such a way as to achieve advance. This interaction is carried out by various sensors and is essential for the proper operation of the industrial robot. The intensity of the interaction increases with the increasing complexity of the task and the degree of dynamic changes in the environment.

6. Mechanical action on the environment - the industrial robot Error! Reference source not found. has manipulation elements that can mechanically act on the environment. [3]

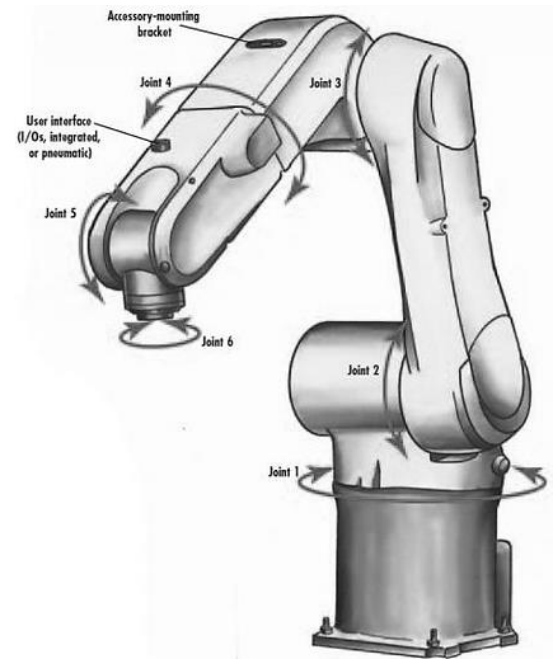

Fig. 1. Industrial robot [4]

Robots application in the industry:

- robot manipulates with technological warhead, through the influence on workpiece (fixtured on the operated desk which one has his own degree of freedom, f.e. work holding device in the arc welding...).

- the robot manipulates with the workpiece (which is based on other technological devices where is realised the appropriate technological operation. 
- robot is without contact of workpiece (arc welding, spraying, plasma cutting).

- robot has contact with workpiece (manipulation, assembly, grinding, spot welding).

- robot operates without information from external sensors (machined workpieces must have the same shape, position and orientation as required for high quality machining).

- robot operates adaptively and on the basis of information from external sensors, corrects the tool guide path over the workpiece, forces and moments of action on the workpiece, respectively and other technological parameters against programmed values.

- the robot works cognitively and, based on information from external sensors, he controls the sequence and the course of all technological operations [5].

Designing an operating process depends on the component, concrete how the resulting assembly or production process will be defined. It depends very much on whether the process is done automatically by an industrial robot or in part of robot-human collaboration $[6,7]$.

Product design requirements for the product manipulation:

- minimizing the number of discrete components that the robot has to manipulate and that are achievable by integrating multiple features into one component,

- the individual components must be easily distinguishable and of defined shape, size and quality without needing of their analyse them during the assembly process,

- the asymmetry of the shape of the components should be significant for ease of feeding, orientation and grip,

- the parts should be designed for easy gripper fixturing without the need for replacement for individual parts

- parts have to be divided and with stabile position and with and with a well-known orientation,

- parts application able to know how to oriented themselves during their inputting,

- parts assembly in vertical direction - from top to bottom (using gravitation),

- ensure installation in the open area without limiting access to the gripper.

\section{The collaborative robots}

Innovations of robotic assembly or production in current are taking place through the introduction of a collaborative robot into the process in collaboration with humans [8]. Compared to industrial and collaborative robots, a comparison of their benefits for practical use is made. The advantage comparison of industrial and collaborative robots is for practical usage as follows Table 1.

Table 1. Comparison of industrial and collaborative robots

\begin{tabular}{|c|c|c|}
\hline Collaborative robots & & Conventional industry robots \\
Simply programming & Programming is time- consuming \\
\hline Lower weigh of robot $<29 \mathrm{~kg}$ & & High weigh of robot $>50 \mathrm{~kg}$ \\
\hline Embedded security features & & Missing of safety sensors \\
\hline Operation in the limited space & & Large operation space \\
Lower weigh of machined workpiece & Greater load capacity \\
\hline Mobile & Immobile \\
\hline External force sensors & & Sensors of external forces are missing \\
\hline Faster and simpler setting & & High operation speed in operation \\
\hline Flexibility of deployment & & Universal usage in the limited space \\
\hline
\end{tabular}




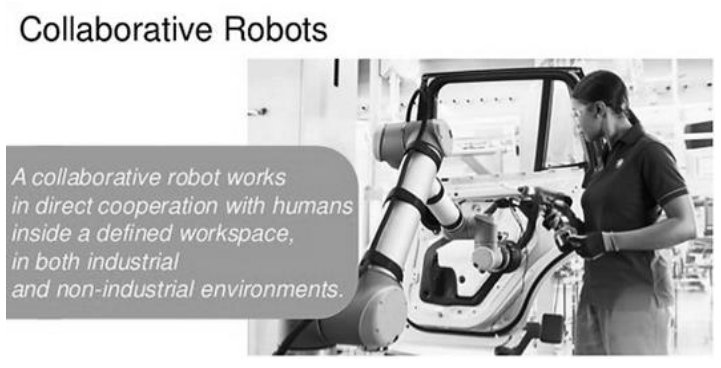

Fig. 2 Usage of collaborative robots [9].

Different businesses deal with the development of collaborative robots that aim to replace the work of a person, or to allow a person and a robot to work together in one workplace. Areas of usage of collaborative robots directly in specific applications in industry are follows: assembly, polishing of surfaces, palletising, packing, workpiece manipulation, painting, supply, welding, positioning, engraving, injection moulding, screwing, grinding, labelling, controlling, bonding, laboratory testing of test-tube and 3D scanning.

\section{Robot system costs}
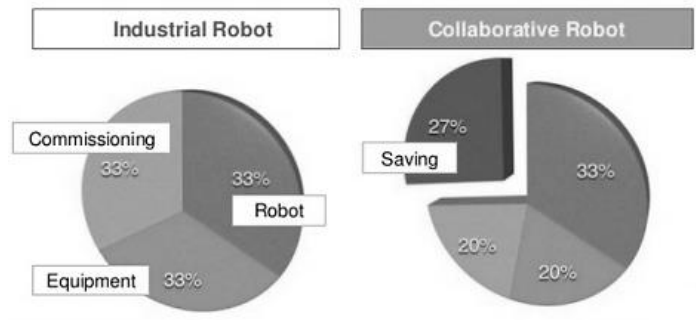

Fig. 3 Costs compare of industrial and collaborative robots [9]

It is essential to deal with the costs invested in industrial robots Fig. . An industrial robot requires a higher commissioning time. The industrial robot provides high productivity and limited flexibility, but high productivity and high flexibility work with the robot.

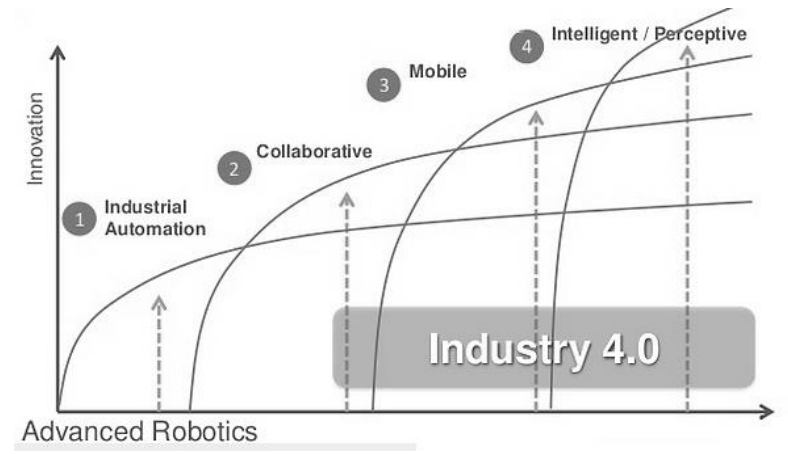

Fig. 4 Development of robotics [9]

\section{Robot comparison via point assessment method}

Point assessment is one of the most accurate and has a great deal of information. A wide range of criteria, which can also be importance, is assessed to increase their specific 
assessment and selection. The most important step is to correctly determine the decision criteria when we want to assess the robots. These may have different wording and, as a rule, concern different areas, they tend to be conflicting. The amount and type of chosen criteria are the support for quality determination for the robot selection. A small number of criteria jeopardize the predicative ability of assess, while a large number of criteria increase the complexity of decisions. For point assessment methods, which are methods of multi-criteria assessment of variants, determining the importance of the criteria is crucial for the reliability and predicative assessment capability. The importance of the criteria expresses the importance of the monitored characteristics, indicators of robots. The higher the importance value, the greater the significance of the criterion. One method for estimating importance values is a point assessment method. The method consists in assigning a certain number of points to each criterion according to its importance. For example, a scale of lower resolution and thus less significance of a given criterion has five points $(1,2,3,4,5)$. The more important the criterion, the more points can be achieved (Table 2) [10].

Table 2. Assessment table based on the given criteria

\begin{tabular}{|c|l|c|c|}
\hline & Value of importance & $\begin{array}{l}\text { Collaborative } \\
\text { robots }\end{array}$ & $\begin{array}{l}\text { Conventional } \\
\text { industry robots }\end{array}$ \\
\hline 1. & Safety and operation speed & 3 & 5 \\
\hline 2. & Price & 2 & 4 \\
\hline 3. & Operation accuracy & 4 & 2 \\
\hline 4. & Operation space & 5 & 3 \\
\hline 5. & Load capacity & 3 & 5 \\
\hline 6. & Programmability & 5 & 2 \\
\hline 7. & Service & 5 & 2 \\
\hline
\end{tabular}

The use of collaborative robots is of most importance in the automotive industry where human labor is being replaced. But the automotive industry and customers still have to make decisions about the main use of the robot. There are still various limitations besides price and technical limitations. A collaborative robot can move at a maximum speed of 250 millimeters per second to be safe. A conventional industrial robot runs at a speed of two meters per second.

The cost of collaborative robots has fallen by 35 percent over the past two years, but is still double that of conventional robots. The collaborative robot is more accurate and eliminates the risk of accidental errors during long-term work but is limited by the safety required when working with humans. The concept of collaborative robots is designed so that the robot automatically stops in the collision and goes into passive mode. Human injury is minimal, but only if the robot does not manipulate with a sharp tool. Even if the force sensor reacts and stops the robot, when handling a sharp tool and in a certain operation space of a person, the impact can be dangerous to the person.

However, each application must initially undergo a risk analysis to ensure $100 \%$ safety in the workplace. Compared to the programming of a collaborative and conventional robot, it is clearly easier to program a collaborative robot that takes about 10 days or sometimes less. Collaborative robots can also be programmed by a trained operator, there is no need for a specialist. It may take several weeks or more to integrate conventional large industrial robots into a production line. Collaborative robots need less operation space to work, but at the same time can manipulates only light workpieces of maximum $10 \mathrm{~kg}$.

In the case of collaborative robots, service costs are minimal, moreover the robots contain no lubricating oil and therefore it is not necessary, as with industrial robots, to replace it after a defined time; there is no cost to buy a license for a programming software tool. 


\section{Conclusions}

Developments in automation advance according to customer requirements Fig. . It is important to respond flexibly and as quickly as possible to the lowest cost of the assembly process. Therefore, it is possible to suppose that collaborative robots later replace the smart mobile and intelligent/perceptive advanced robotics.

This article shows the advantages and disadvantages of both types of robots, but each one of them has its legitimate use. While it is expected to replace humans with robots (concrete collaborative), their introduction into industry will be a longer term of process, since certain industrial operations can be operated only by man.

Acknowledgement: The contribution is sponsored by the project n. 021STU-4/2018 named Development of a laboratory for the design and maintenance of production systems supported by the use of Virtual Reality.

\section{References}

1. P. Demeč and J. Svetlík. Production machines. Košice, Publisher: Technical University in Košice, (2016), pp. 167, ISBN 978-80-553-3070-9

2. O. Moravčík, P. Božek. Angular robot in a virtual environment. In Research papers of Faculty of Materials Science and Technology Slovak University of Technology in Trnava. 24 (2008), pp. 119-123.

3. Javorová, M. Kusá, "Robotic system design with CA system support." In Applied Mechanics and Materials: ROBTEP 2014, Štrbské Pleso, (2014), pp. 208-213. ISSN $1660-9336$.

4. S. Mraz. „High speed robots in an assembly line.“ Internet: http://www.machinedesign.com/robotics/high-speed-robot-assembly-line, Sep. 04, (2003) [Jun. 26, 2018]

5. P. Božek, O. Barborák, L. Naščák and V. Štollmann. Specialist robotics systems. Ostrava: Ámos, (2011), pp. 224.

6. O. Staš, M. Tolnay, „Objectification of quality parameters of robotic structures.“ In Advances in mechanical engineering. Proceedings 1st. international scientific conference. Debrecen, Hungary, (2013), pp. 164-168, ISBN 978-963-473-623-3.

7. M. Tolnay, M. Bachratý and O. Staš. Objectification of quality parameters in robot structures by criterion functions. In IMT Oradea 2013: Proceedings of the annual session of scientific papers, 2013. Oradea: University of Oradea Publishing House, (2013), pp. 231-234. ISBN 978-606-10-1084-4

8. Š. Václav, J. Jurko, Š. Lecký. "Allowance treatment static designed couple and repeatable precision in assembly". In MATEC Web of Conferences. Vol. 137, Modern Technologies in Manufacturing (MTeM 2017 - AMaTUC), Cluj-Napoca, Romania, October 12-13, (2017), online, ISSN 2261-236X.

9. Unknown. "Industry 4.0: Smart robots for smart factories." Website: https://www.slideshare.net/empresaenxarxa/industry-40-smart-robots-for-smartfactories, May 6, (2015), [Jun.20, 2018].

10. J. Fotr, J. Dědina, H. Hrůzová. Manažerské rozhodování. Praha: Ekopress (2000), pp. 231. ISBN 80-86119-20-3 